\title{
Measles Virus N mRNA
}

National Cancer Institute

\section{Source}

National Cancer Institute. Measles Virus N mRNA. NCI Thesaurus. Code C118890.

An olig oribonucleotide ( 1.7 kbp) transcribed by RNA-dependent RNA polymerase from

the measles virus $\mathrm{N}$ gene negative-sense RNA. This mRNA can be translated by host

ribosomes to produce measles virus nucleoprotein, which is involved in viral

encapsidation. 